\title{
Variáveis que influenciaram o IDEB do ensino fundamental das redes públicas municipais paulistas em 2017
}

\author{
Jaime Crozatti ${ }^{1}$ \\ ORCID: 0000-0002-3789-8761
}

\section{Resumo}

Considerando a contínua necessidade de melhorar a condição da educação brasileira e o momento da renovação da principal Lei de financiamento da educação nos municípios no ano de 2020, este artigo tem como objetivo identificar as variáveis do contexto educacional das redes do ensino fundamental dos municípios paulistas, as quais têm correlação significativa com o IDEB, do ano de 2017. Utiliza-se de 33 variáveis, dentre as indicadas pela literatura, as quais têm dados disponíveis em sites oficiais do governo e os analisa com o método dos Mínimos Quadrados Ordinários (MQO) e o procedimento stepwise. A equação de regressão obtida no estudo mostra que o gasto médio por aluno com o pessoal próprio das redes municipais, o esforço docente, o abandono escolar bem como o índice de desenvolvimento da dimensão renda explicam, com significância estatística de 5\%, mais de 66\% do IDEB, do ano de 2017 das redes municipais no estado de São Paulo. Os resultados corroboram a literatura nacional e internacional para a figura do professor, sua remuneração e a gestão do processo escolar como os elementos-chave para o desenvolvimento da educação. 0 momento pede postura de melhores investimentos, com planejamento e execução coerentes no contexto social e econômico, específicos do desenvolvimento da atividade educacional, com atenção para os espaços escolares, os recursos financeiros e os profissionais que ali trabalham.

\section{Palavras-chave}

IDEB - Redes municipais - Ensino fundamental - Qualidade na educação.

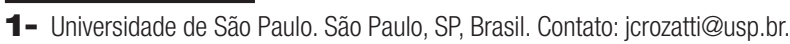




\title{
Variables influencing the elementary education IDEB in public municipal networks of São Paulo in 2017
}

\begin{abstract}
Considering the continuous need to improve the condition of Brazilian education and the moment of renewal of the main Law on financing education in municipalities in 2020, this article aims to identify the variables of the context of elementary education networks in São Paulo municipalities, which have a significant correlation with the IDEB, in 2017. Among those indicated in the literature, 33 variables are used, which have data available on official government websites, and analyzed using the Ordinary Least Squares (OLS) method and the stepwise procedure. The regression equation obtained in the study shows that the average expenditure per student on staff of the municipal networks, teaching effort, school dropout, as well as the development index of the income dimension explain, with a statistical significance of 5\%, more than 66\% of IDEB of municipal networks in the state of São Paulo in 2017. The results corroborate the national and international literature regarding the figure of the teacher, his remuneration, and the management of the school process as the key elements for the development of education. The moment calls for a posture of better investments, with coherent planning and execution in the social and economic context, specific to the development of educational activity, with attention to school spaces, financial resources and the professionals who work there.
\end{abstract}

\section{Keywords}

IDEB - Municipal networks - Elementary education - Quality in education.

\section{Introdução}

Desde que o IDEB - Índice de Desenvolvimento da Educação Básica (BRASIL, 2019b) foi instituído como potencial indicador de qualidade da educação básica (BRASIL, 2007), não é difícil aceitar a ideia de que uma das informações desejadas por gestores e pelos cidadãos é saber em quais programas aplicar recursos, com o intuito de melhorar o desempenho neste indicador. A bibliografia da área sugere que não se pode afirmar que programas contemplando um componente (variável) (WOOLDRIDGE, 2016, p. 23) ou mesmo um fator (combinação de variáveis) (HAIR et al., 2009, p. 101) teriam a primazia na explicação do desempenho dos alunos, em sistemas de avaliação geral e na esperada progressão para as séries seguintes. Há tempos analistas sugerem que há considerável combinação de componentes, com distintas associações para cada contexto e momento, tornando a questão complexa (OLIVEIRA, 2010; DITTRICH, 2010). Pode-se ver que o termo 
qualidade, quando atribuído à educação, torna-se polissêmico, haja vista que esta pode ser interpretada por diferentes perspectivas (GUSMÃO, 2013; ALVEZ; SILVA, 2013).

Fatores relacionados às características pessoais e familiares dos alunos, das estruturas macro econômicas e sociais até àquelas que se podem identificar com as estruturas da oferta do serviço público, presentes nas localidades onde as atividades são desenvolvidas, estão entre as mais indicadas como influenciadoras nos resultados dos sistemas educacionais (OLIVEIRA, 2010). Estes últimos caracterizam as condições da efetiva produção da política pública em um território (MORAES, 2018), resultados das escolhas públicas realizadas pelos atores políticos responsáveis pela gestão dos serviços públicos nas localidades (SECHI, 2015).

Há considerável interesse da academia em estudos sobre o IDEB, como indicador da qualidade, com a avaliação da eficiência do gasto, como foco de maior frequência. Poucos estudos publicados procuram explicar os influenciadores do IDEB em redes municipais do ensino fundamental. Tal constatação indica uma lacuna a ser preenchida por estudos capazes de subsidiar as avaliações dos cidadãos e decisões dos responsáveis pela gestão dos programas e das políticas educacionais nos municípios.

Diante desse contexto, este artigo tem o objetivo precípuo identificar e avaliar variáveis com maior nível de associação com o IDEB dos alunos do ensino fundamental, anos iniciais e fınais, matriculados nas redes públicas municipais paulistanas, no ano de 2017. Com base na literatura visitada e referida no tópico seguinte, o estudo usa variáveis obtidas em bases de dados oficiais da União e do Estado de São Paulo, aplicando técnicas de análises simples e multivariada pelos Mínimos Quadrados Ordinários (WOOLDRIGE, 2016, p. 70) para identificar as que influenciaram, com maior nível de significância estatística (HAIR et al., 2009) o IDEB do ensino fundamental, das redes municipais do Estado de São Paulo, no ano de 2017.

Com a crescente disponibilização em sites oficiais de governos dos bancos de dados educacionais, este estudo usa dados do TCE - Tribunal de Contas do Estado (SÃO PAULO, 2019), do IBGE - Instituto Brasileiro de Geografia e Estatística (BRASIL, 2020a), da STN - Secretaria do Tesouro Nacional (BRASIL, 2020b), do IDEB - Índice de Desenvolvimento da Educação Básica (BRASIL, 2019a), do INEP - Instituto de Estudos e Pesquisa Anísio Teixeira (BRASIL, 2019b) bem como do MS - Ministério da Saúde (BRASIL, 2019e).

No modelo de regressão há 33 variáveis indicadas pela literatura as quais contavam com dados disponíveis em nível municipal nas fontes citadas, para o ano de 2017. Pelo procedimento stepswise (FAVERO, 2015, 44) foram definidas as variáveis que representam a influência com maior significância estatística ( $p$-value $>0,05)$ no IDEB de 2017 das redes municipais paulistas do ensino fundamental. 0 resultado anterior do IDEB, de 2015, índice de desenvolvimento humano dimensão renda do ano de 2010, taxa de esforço docente, a de abandono dos estudantes e a remuneração média por aluno do pessoal próprio das redes municipais, apontam como os influenciadores explicativos de mais de 66\% do IDEB dos municípios.

0 ineditismo deste estudo se refere à baixa disponibilidade de publicações com objetivos similares. É oportuno pela renovação, em 2020, da Lei do Fundo de Manutenção e Desenvolvimento da Educação Básica e de Valorização dos Profissionais da Educação Fundeb (BRASIL, 2019d), que colocou na agenda pública as políticas educacionais e seu 
financiamento. Há de se considerar que as transferências federais são as mais relevantes no financiamento da educação nos municípios brasileiros, agravando o cuidado na renovação da referida Lei. Outro ponto diz respeito à avaliação da qualidade do ensino fundamental na perspectiva da gestão da qualidade do gasto público (BOUERI et al., 2015).

Além desta introdução, este artigo visita estudos publicados sobre o IDEB e a qualidade do ensino contextualizando e dando suporte às descobertas. Na sequência, apresenta as escolhas metodológicas, os resultados e as conclusões.

\title{
O IDEB, as publicações e a qualidade da educação pública
}

\section{IDEB - Índice de Desenvolvimento da Educação Básica}

\author{
Segundo o INEP: \\ 0 Ideb é um indicador de qualidade educacional que combina informações de desempenho em \\ exames padronizados (Prova Brasil ou Saeb) - obtido pelos estudantes ao fınal das etapas de \\ ensino ( $4^{\mathrm{a}}$ e $8^{\mathrm{a}}$ séries do ensino fundamental e $3^{\mathrm{a}}$ série do ensino médio) - com informações sobre \\ rendimento escolar (aprovação). (BRASIL, 2019b, p. 1).
}

Criado em 2007 com base na "aplicação de um mecanismo de avaliação com características sensitivas, denominado Prova Brasil” de 2005 (DITTRICH, 2010, p. 1), o IDEB foi instituído pelo INEP depois da fase de inclusão das crianças brasileiras nas redes de ensino em meados da década de 1990, "quando finalmente o Ensino Fundamental foi praticamente universalizado" (OLIVEIRA, 2010, p. 12). No ano de 2007, por meio do Decreto de $n^{\circ} 6.094$ de 24 de abril de 2007 (BRASIL, 2007), o então Presidente da República, Sr. Luiz Inácio Lula da Silva, instituiu este indicador com a determinação de que:

\footnotetext{
Art. $3^{\circ} \mathrm{A}$ qualidade da educação básica será aferida, objetivamente, com base no IDEB, calculado e divulgado periodicamente pelo INEP, a partir dos dados sobre rendimento escolar, combinados com o desempenho dos alunos, constantes do censo escolar e do Sistema de Avaliação da Educação Básica - SAEB, composto pela Avaliação Nacional da Educação Básica - ANEB e a Avaliação Nacional do Rendimento Escolar (Prova Brasil). (BRASIL, 2007, p. 1).
}

O IDEB combina a progressão no sistema de ensino com o necessário aprendizado dos conteúdos adequados para cada série (REZENDE; JANUZZI, 2008, p. 121; BRASIL, 2019b), uma vez que "combina informações de desempenho em exames padronizados (Prova Brasil ou Saeb) - obtido pelos estudantes ao final das etapas de ensino ( $4^{\mathrm{a}}$ e $8^{\mathrm{a}}$ séries do ensino fundamental e $3^{\text {a }}$ série do ensino médio) - com informações sobre rendimento escolar (aprovação)" (BRASIL, 2019b, p. 1). Sua implementação "representa uma mudança de paradigma, uma vez que nossa tradição em desenvolvimento de indicadores educacionais para uso em política educacional é pequena ou, quando muito, localizada em alguns setores técnicos" (VIDAL; VIEIRA, 2011, p. 426) e constitui-se um campo fértil para a 
avaliação da educação brasileira visando a diminuição das desigualdades educacionais (FRANKLIN, 2011, p. 232).

\section{Estudos sobre o IDEB}

As bases SCIELO (www.scielo.br) e SPELL (www.spell.org.br) contemplam 123 periódicos nacionais do QUALIS/CAPES das áreas de educação dos "países em desenvolvimento e particularmente na América Latina e Caribe” (SCIELO, 2019, p. 1) e de administração (SPELL, 2019). Com o termo IDEB nas ferramentas de busca foram encontrados 65 artigos (29 na Spell e 37 na Scielo, 1 repetido), publicados em 45 distintos periódicos de instituições brasileiras. 0 mais antigo é de 2007 e 5 cinco publicados em 2019, até agosto. 0 periódico que mais publicou artigos (9) foi o Ensaio: Avaliação e Políticas Públicas em Educação (http://revistas.cesgranrio. org.br/index.php/ensaio). Outros quatro periódicos publicaram quatro ou cinco artigos; 24 periódicos têm a publicação de um único artigo. Nos anos de 2013, 2016 e 2018 houve mais publicações (11, 11 e 10, respectivamente). De 2013 até o momento, há o mínimo de cinco artigos publicados por ano nestes 45 periódicos, mostrando a relativa novidade do tema. Destacamos quatro artigos dentre os que têm similaridade com o objetivo deste estudo.

Rezende e Januzzi (2008), ao analisarem as condições para a formalização do IDEB, validaram que "O Ideb foi construído com uma metodologia consistente que usa duas dimensões semelhantes, compostas por indicadores de resultado que se afetam mutuamente em sentidos opostos" (REZENDE; JANUZZI, 2008, p. 144) propondo a inclusão da "dimensão do abandono escolar" como uma das dimensões importantes do desenvolvimento educacional nos últimos 10 anos (REZENDE; JANUZZI, 2008, p. 144).

0 estudo de Alves e Soares (2013) abordou:

[...] a complexa relação entre o valor do Ideb da escola e suas características contextuais definidas pelo perfil de seus alunos e pelas condições da oferta escolar. Para tanto, faz uso dos dados da Prova Brasil, do Censo Escolar e do Ideb, referentes às escolas públicas de ensino fundamental de todo o Brasil que possuem essas informações divulgadas pelo Inep. (ALVES; SOARES, 2013, p. 179).

Consideram que "As condições de infraestrutura e de complexidade da escola medidas com os dados do Censo Escolar - também guardam relação significativa com o Ideb" (ALVES; SOARES, 2013, p. 191).

Lourenço et al. (2016) avaliam se a distinção de nota do IDEB entre os municípios brasileiros pode ser consequência de aspectos sociais, econômico-financeiros e de controle social, além dos pedagógicos e estruturais e concluíram que:

[...] aspectos sociais e pedagógicos são determinantes para a probabilidade de obtenção de notas regulares ou boas notas no IDEB 2013; e que municípios pertencentes a Estados com maior concentração de riqueza, com menor acesso ao conhecimento e baixa expectativa de vida têm um incremento relevante na probabilidade de obtenção de notas ruins no IDEB. A pesquisa contribui com evidências de que fatores contextuais, contingenciais e locais, inclusive àqueles relacionados às condições familiares e habitacionais, exercem maior impacto sobre o desempenho escolar do que fatores relacionados aos gastos públicos com educação básica. (LOURENÇO et al., 2016, p. 28-29). 
Assim, mostra como o desempenho no ensino é influenciado por diversos fatores contextuais.

0 trabalho de Gomes et al. (2016) "teve como objetivo estudar as políticas de desenvolvimento social de três municípios paulistas: Americana, Cajuru e São Caetano do Sul, a partir de indicadores sociais e econômicos, conjugando-os com os resultados educacionais." (GOMES et al., 2016, p. 36). Combinaram a visão de gestores, docentes e pais ou cuidadores da oferta e demanda dos serviços de educação com dados secundários do IBGE, Fundação Seade e EducaCenso/Ideb nos anos 2007, 2009, 2011 e 2013. Avaliaram que: "[...] índices de riqueza e de desenvolvimento não estão diretamente correlacionados ao desempenho da educação pública local, assim como escola de tempo integral não é por si só representante de melhor qualidade de ensino" (GOMES et al., 2016, p. 36). Concluem que:

[...] há evidências de que a melhoria da qualidade do ensino está mais relacionada à gestão, ao comprometimento, à responsabilidade, à formação e à avaliação do que ao volume de recursos aplicados. Às melhorias das condições salariais dos educadores deve-se acrescentar um conjunto de medidas e estruturais (sic), de gestão, saindo do difuso compromisso dos discursos políticos. Observou-se também uma alta sensibilidade dos educadores com relação às mudanças, principalmente as decorrentes de processos eleitorais e da gestão executiva do município. (GOMES et al., 2016, p. 48).

Sanches (2017) fez um rico levantamento de teses e dissertações da base da CAPES - Coordenação de Aperfeiçoamento de Pessoal de Nivel Superior - com o "objetivo geral de analisar quais pesquisas, concluídas no Brasil entre 2007 e 2015, fazem referência ao Ideb, identificando modalidades de apropriação do Índice nestas produções”. Após a análise dos 383 trabalhos encontrados, avaliou:

Cinco formas predominantes na incorporação do tema: referência ao Ideb como indutor de políticas e programas; investigação de fatores para obtenção de alto ou de baixo Ideb por escolas ou redes públicas de ensino; referência ao Ideb como indicador de resultado de programas/políticas/gestão; uso de dados do Ideb no delineamento da pesquisa e/ou na análise dos dados, tratado usualmente como uma das variáveis explicativas dos resultados do estudo; e menção ao Ideb como um dos critérios de seleção de estados, municípios e/ou escolas a serem pesquisadas ou como elemento de caracterização do contexto de realização do estudo. (SANCHES, 2017, p. 151).

Este estudo evidencia que o IDEB é valorizado pela sociedade como "elemento indutor" de políticas, usado em distintos níveis do processo educativo, os quais incluem a gestão das redes e a sala de aula uma vez que é associado à noção de qualidade educacional.

Diante do exposto, pela amplitude de usos do indicador pode-se considerar que a comunidade acadêmica tem se debruçado sobre o tema com profusão de análises, representando um caminho bem pavimentado no tocante à gestão das políticas públicas da educação básica brasileira.

$\mathrm{Na}$ literatura internacional, os estudos sobre desempenho escolar tem relação com o gasto nas estruturas de oferta do serviço para análise da eficiência do recurso, com a ferramenta da Análise Envoltória de Dados (DEA, do inglês Data Envelopment Analysis). 
Moraes (2018) mapeou estes estudos publicados nas bases ERIC (Educational Resources Information Center) e WOS (Web of Science), de 1978 a 2016. Os fatores apontados estão atrelados ao âmbito do aluno, da família ou da instituição de ensino, os quais podem ser descritos como: psicológicos e comportamentais, demográficos, necessidades econômicas, estrutura familiar, educação dos pais, taxa de frequência à escola, recursos educacionais, número de estudantes, proporção de professor por aluno, experiência docente e as despesas/gastos públicos propriamente, que estão mais relacionados às variáveis como salário do professor, pessoal (equipe acadêmica, administradores e equipe de apoio) e recursos escolares (livros, computadores, edificações etc.) (MORAES, 2018, p. 48-68).

Em seu estudo, Moraes (2018, p. 139) concluiu que a eficiência dos municípios brasileiros na política pública do ensino fundamental pode ser analisada por variáveis que qualificam a estrutura de funcionamento da rede municipal do ensino fundamental (adequação docente, complexidade da gestão, esforço docente, rotatividade docente, remuneração docente e infraestrutura escolar), as quais definem cinco "Tipologias" de municípios. Estas tipologias e os resultados das redes suportam sua afirmação de que "para a melhoria da qualidade de quaisquer indicadores, é necessário levar em consideração o perfil da municipalidade em questão para melhor precisão no diagnóstico de quais ações devem ser formuladas e implementadas." (MORAES, 2018, p. 140). Estes fatores de influência são traduzidos nas variáveis usados no presente estudo.

\section{Aspectos metodológicos}

0 presente estudo pode ser classificado como exploratório descritivo e explicativo, haja vista o objetivo de identificar as variáveis com significativa correlação com o IDEB, no ano 2017, das redes municipais do ensino fundamental no Estado de São Paulo, já que analisa "se e como duas ou mais variáveis estão relacionadas uma com a outra numa população” (STEVENSON, 1981, p. 341). Para tanto, faz uso da técnica de análise de regressão multivariada (HAIR et al., 2009, p. 149-220) pelos Mínimos Quadrados Ordinários (WOOLDRIDGE, 2016) e o procedimento stepwise que "apresenta a propriedade de automaticamente excluir as variáveis explicativas cujos parâmetros não se mostrarem estatisticamente diferentes de zero" (FÁVERO, 2015, p. 44).

A cidade de São Paulo foi excluída tendo em vista que tem população equivalente a $42 \%$ das demais e orçamento público, para 2017, equivalente $49,4 \%$ da soma do orçamento de todos os municípios do estado (BRASIL, 2020b). Os 644 remanescentes foram agrupados por sua população estimada pelo IBGE de 2017, em cinco faixas, conforme divulgado pela Secretaria do Tesouro Nacional (BRASIL, 2020b):

Faixa 1 - até 30.000 habitantes

Faixa 2 - entre 30.001 e 50.000 habitantes

Faixa 3 - entre 50.001 e 300.000 habitantes

Faixa 4 - entre 300.001 e 1.000 .000 de habitantes

Faixa 5 - acima de 1.000.000 de habitantes 
As variáveis utilizadas, indicadas na literatura e com dados disponíveis, estão descritas no Quadro 1, a seguir, quanto à denotação usada na regressão, descrição e fonte.

Quadro 1- Variáveis utilizadas no modelo de regressão múltipla com procedimento stepwise: denotação no modelo (sigla), descrição e fonte

\begin{tabular}{|c|c|c|}
\hline Variável & Descrição & Fonte \\
\hline ideb17 & $\begin{array}{l}\text { Índice de Desenvolvimento da Educação Básica das escolas das redes municipais paulistas do ensino } \\
\text { fundamental, do ano de } 2017 \text {. }\end{array}$ & BRASIL, 2019c \\
\hline ideb15 & $\begin{array}{l}\text { Índice de Desenvolvimento da Educação Básica das escolas das redes municipais paulistas do ensino } \\
\text { fundamental, do ano de } 2015 \text {. }\end{array}$ & BRASIL, 2019c \\
\hline tdi17 & $\begin{array}{l}\text { Taxa da Distorção Idade Série. Refere-se à taxa de defasagem entre a idade do aluno e a série que o aluno } \\
\text { deveria estar matriculado, caso seguisse o fluxo regular no ensino fundamental, quando iniciado aos cinco ou } \\
\text { seis anos de idade. }\end{array}$ & BRASIL, 2019c \\
\hline abd17 & Taxa de abandono de alunos, identificado pela comparação das matrículas entre o início e o final do ano 2017. & BRASIL, 2019c \\
\hline inse17 & Índice do nível sócio econômico dos alunos matriculados na rede municipal do ensino fundamental, em 2017. & BRASIL, 2019c \\
\hline $\operatorname{tnr} 17$ & Taxa de não-resposta. Representa a proporção de alunos com ausência de dados, nos bancos de dados do INEP. & BRASIL, 2019c \\
\hline afd17 & $\begin{array}{l}\text { Adequação da Formação Docente. Percentual de docentes no Ensino Fundamental, em escolas municipais por grupo } \\
\text { de adequação da formação à disciplina lecionada, em 2017. Referem-se a: Grupo } 1 \text { - Docentes c/formação superior } \\
\text { de licenciatura (ou bacharelado c/ complementação pedagógica) na mesma área da disciplina lecionada; e Grupo } 2 \text { - } \\
\text { Docentes c/formação superior de bacharelado (s/ complementação pedagógica), na mesma área da disciplina lecionada. }\end{array}$ & BRASIL, 2019c \\
\hline dsu17 & Percentual de Docentes no Ensino Fundamental da rede municipal, com curso superior, no ano de 2017. & BRASIL, 2019c \\
\hline had17 & $\begin{array}{l}\text { Média de Horas/Aulas por dia. Não há nota técnica no site do INEP sobre esta variável. Foi considerado } 0 \\
\text { informado pelos municípios ao INEP. }\end{array}$ & BRASIL, 2019c \\
\hline ied17 & $\begin{array}{l}\text { Índice de esforço docente. Classifica cada docente em níveis de } 1 \text { a } 6 \text {, de acordo com o esforço empreendido } \\
\text { no exercício da profissão. Níveis elevados indicam maior esforço, já que estão relacionados às seguintes } \\
\text { características da docência: } n^{0} \text { de escolas em que atua, } n^{0} \text { de turnos de trabalho, } n^{0} \text { de alunos atendidos e } n^{0} \\
\text { de etapas nas quais leciona. Foram tomados os percentuais de docentes atuantes nos níveis } 1 \text { e } 2 \text {, ou seja, a } \\
\text { proporção dos docentes de cada rede que, em geral, tem até } 25 \text { ou entre } 25 \text { e } 150 \text { alunos e atuam em um único } \\
\text { turno, escola e etapa, níveis considerados de menor esforço. }\end{array}$ & BRASIL, 2019c \\
\hline ird17 & $\begin{array}{l}\text { Taxa de Regularidade Docente. Avalia a regularidade do corpo docente nas escolas de educação básica, a partir } \\
\text { da observação da permanência dos professores nas escolas nos últimos cinco anos (2013 a 2017). Varia de } 0 \text { a } \\
5 \text {, quanto mais próximo de } 0 \text {, mais irregular é o vínculo do docente com a escola. As escolas foram classificadas } \\
\text { pelas seguintes faixas do indicador de regularidade: baixa regularidade (IRD médio igual ou menor que 2); média- } \\
\text { baixa (IRD médio maior que } 2 \text { até 3); média-alta (IRD médio maior que } 3 \text { até 4); alta (IRD médio maior que } 4 \text { até } \\
\text { 5). Para este estudo foram tomadas as proporções de docentes nos IRD média alta e alta. }\end{array}$ & BRASIL, 2019c \\
\hline rmd17 & $\begin{array}{l}\text { Remuneração média dos docentes. Refere-se à remuneração bruta padronizada para } 40 \text { horas dos docentes, em } \\
\text { exercício na educação básica por município e escolaridade, em } 2014 .\end{array}$ & BRASIL, 2019c \\
\hline atu17 & Alunos por turma: “divisão do número de matrículas pelo número de turmas” (BRASIL, 2019c). & BRASIL, 2019c \\
\hline conedu & Existência de Conselho Municipal de Educação, 0 para não, 1 para sim. & BRASIL, 2019c \\
\hline confund & $\begin{array}{l}\text { Existência de Conselho Municipal de Gestão do FUNDEB - Fundo de Desenvolvimento da Educação Básica, } 0 \\
\text { para não, } 1 \text { para sim. }\end{array}$ & BRASIL, 2019c \\
\hline gestrec & Existência de Conselho Gestor da Receita com a Educação no município, 0 para não, 1 para sim. & BRASIL, 2019c \\
\hline sme & Existência de estrutura administrativa autônoma da Secretaria Municipal de Educação, 0 para não, 1 para sim. & BRASIL, 2019c \\
\hline plano & Existência de Plano Municipal de Educação, 0 para não, 1 para sim. & BRASIL, 2019c \\
\hline rc17 & Receita Corrente total arrecadada pelo município, no ano de 2017. & BRASIL, 2020b \\
\hline
\end{tabular}




\begin{tabular}{|c|c|c|}
\hline $\operatorname{rcc} 17$ & Receita Corrente per capta municipal, no ano de 2017. & \begin{tabular}{|c|} 
Com base em \\
BRASIL, 2020a \\
e BRASIL, \\
2020b.
\end{tabular} \\
\hline fundb17 & Valor total do Fundeb recebido em 2017. & BRASIL, 2020b \\
\hline fundeba17 & Valor médio por aluno, do valor do FUNDEB recebido pelo município, no ano de 2017. & \begin{tabular}{|c|} 
Com base em \\
BRASIL, 2019b \\
e BRASIL, \\
2020b.
\end{tabular} \\
\hline gini10 & $\begin{array}{l}\text { Indicador do grau de concentração de renda municipal, entre os mais ricos e os mais pobres. Quanto mais } \\
\text { próximo de } 1 \text {, maior o nível de distribuição de renda deste grupo. }\end{array}$ & BRASIL, 2019e \\
\hline idhm10 & Índice de Desenvolvimento Humano global municipal do ano de 2010. & BRASIL, 2020a \\
\hline idhe10 & Índice de Desenvolvimento Humano, dimensão educação, do ano de 2010. & BRASIL, 2020a \\
\hline idhl10 & Índice de Desenvolvimento Humano, dimensão longevidade, em 2010. & BRASIL, 2020a \\
\hline idhr10 & Índice de Desenvolvimento Humano, dimensão renda, do ano de 2010. & BRASIL, 2020a \\
\hline pibt16 & Produto Interno Bruto total do município, no ano de 2016 & $\begin{array}{l}\text { BRASIL, } \\
2020 \mathrm{a}\end{array}$ \\
\hline pibc16 & Produto Inter Bruto per capta do município, no ano de 2016. & $\begin{array}{l}\text { BRASIL, } \\
2020 \mathrm{a}\end{array}$ \\
\hline ma17 & $\begin{array}{l}\text { Média do gasto orçamentário por aluno, com a remuneração e/ou benefícios pagos para os profissionais do } \\
\text { ensino fundamental municipal. }\end{array}$ & $\begin{array}{l}\text { Com base em } \\
\text { SÃO PAULO, } \\
2019\end{array}$ \\
\hline $\mathrm{mb} 17$ & Média do gasto orçamentário por aluno com viagens e estadas do ensino fundamental municipal. & $\begin{array}{l}\text { Com base em } \\
\text { SÃO PAULO, } \\
2019\end{array}$ \\
\hline mc17 & Média do gasto orçamentário por aluno, com juros e encargos financeiros do ensino fundamental municipal. & $\begin{array}{c}\text { Com base em } \\
\text { SÃO PAULO, } \\
2019\end{array}$ \\
\hline md17 & Média do gasto orçamentário por aluno, com compras de materiais e serviços. & $\begin{array}{c}\text { Com base em } \\
\text { SÃO PAULO, } \\
2019\end{array}$ \\
\hline me17 & Média do gasto por aluno, com materiais permanentes e investimentos fixos do ensino fundamental municipal. & $\begin{array}{c}\text { Com base em } \\
\text { SÃO PAULO, } \\
2019\end{array}$ \\
\hline
\end{tabular}

Fonte: Elaboração própria.

Os requisitos de normalidade, homocedasticidade e linearidade (HAIR et al., 2009, p. 82-88; CORRAR; PAULO; DIAS FILHO, 2014, p. 40-46) e da ausência da multicolinearidade (HAIR et al., 2009, p. 160; FÁVERO et al., 2014, p. 131; FÁVER0, 2015, p. 45-62) das variáveis da regressão final, foram verificados e achados adequados pelo teste visual do histograma, pelos testes de White, Shapiro-Wilk e da correlação linear e o fator de inflação da variância ou VIF (Variance Inflation Fator) (HAIR et al., 2009, p. 190-191; FÁVERO et al., 2014, p. 131-142; FÁVERO, 2015, p. 45-62). Os dados, quadros, gráficos e análises estatísticas foram desenvolvidos com os aplicativos Microsof Excel (2010) e STATA (14) [Programas de Computador].

\section{Resultados e análises}


A população residente, os alunos matriculados e o respectivo IDEB do ano de 2017 (média, menor e maior valor e desvio padrão) na rede municipal do ensino fundamental dos 644 municípios, estão contidas no Tabela 2 abaixo, nas faixas de população já identificadas.

Tabela 2- População, alunos matriculados, média, menor e maior valor e desvio padrão do IDEB de 2017 , da rede municipal no Estado de São Paulo, por faixa da população

\begin{tabular}{|c|c|c|c|c|c|c|c|c|c|}
\hline \multirow[b]{2}{*}{$\begin{array}{l}\text { Faixa da } \\
\text { população }\end{array}$} & \multirow{2}{*}{$\begin{array}{l}\text { Qtde. de } \\
\text { Municípios. }\end{array}$} & \multirow[b]{2}{*}{ População } & \multirow[b]{2}{*}{ Taxa } & \multirow{2}{*}{$\begin{array}{l}\text { Total de matrículas } \\
\text { na educ. fundam. }\end{array}$} & \multirow[b]{2}{*}{ Taxa } & \multicolumn{4}{|c|}{ IDEB de 2017} \\
\hline & & & & & & Média & Menor & Maior & $\begin{array}{l}\text { Desvio } \\
\text { Padrão }\end{array}$ \\
\hline 1 & 268 & 1.367 .587 & $4 \%$ & 99.069 & $5 \%$ & 6,37 & 4,40 & 7,80 & 0,68 \\
\hline 2 & 240 & 5.617 .178 & $17 \%$ & 393.281 & $22 \%$ & 6,18 & 4,35 & 7,80 & 0,65 \\
\hline 3 & 112 & 13.107 .592 & $40 \%$ & 796.449 & $44 \%$ & 6,19 & 4,85 & 7,40 & 0,55 \\
\hline 4 & 22 & 10.362 .941 & $31 \%$ & 461.851 & $25 \%$ & 6,10 & 4,95 & 7,10 & 0,60 \\
\hline 5 & 2 & 2.531 .542 & $8 \%$ & 71.186 & $4 \%$ & 5,90 & 5,60 & 6,20 & 0,42 \\
\hline Total & 644 & 32.986 .840 & $100 \%$ & 1.821 .837 & $100 \%$ & 6,25 & 4,35 & 7,80 & 0,65 \\
\hline
\end{tabular}

Fonte: Elaboração própria.

Legenda: Faixa 1: até 30.000 habitantes; Faixa 2: entre 30.001 e 50.000 habitantes; Faixa 3: entre 50.0001 e 300.000 habitantes; Faixa 4: entre 300.001 e 1.000.000: Faixa 5: acima de 1.000 .000 de habitantes.

No Tabela 2 acima, observa-se que 21\% dos paulistas, exceto a capital, residem em municípios com até 50 mil habitantes. Estes municípios abrigam mais de 27\% dos alunos matriculados em escolas do ensino fundamental geridas pelas prefeituras locais. Têm também o menor e o maior valor do IDEB no ano de 2017 na rede municipal do ensino fundamental do Estado. Observa-se que, enquanto há municípios com IDEB em níveis superiores $(7,80)$ à média do estado $(6,25)$, nestas cidades há também o menor $\operatorname{IDEB}(4,35)$.

0 Tabela 3, a seguir, apresenta as variáveis que foram excluídas da regressão multivariada pelo procedimento stepwise (FÁVERO, 2015, p. 44) por apresentarem baixa significância estatística ( $p$-value $>0,05$ ), com a variável dependente no modelo de regressão.

Tabela 3- Variáveis removidas pelo aplicativo do modelo de regressão, com o procedimento stepwise, por terem significância estatística inferior a 5\% (p-value > 0,05)

\begin{tabular}{|c|c|c|c|c|c|}
\hline Variável & $p$-value & Variável & $p$-value & Variável & $p$-value \\
\hline me17 & 0.9528 & mb17 & 0.6568 & atu17 & 0.3800 \\
\hline inse17 & 0.9406 & idhm10 & 0.5690 & gini10 & 0.2051 \\
\hline fundb17 & 0.9208 & rcc17 & 0.5415 & md17 & 0.1823 \\
\hline sme & 0.9045 & $\mathrm{rc} 17$ & 0.5224 & gestrec & 0.1707 \\
\hline pibt16 & 0.8970 & ird17 & 0.5032 & plano & 0.1347 \\
\hline confund & 0.8521 & dsu17 & 0.4256 & tdi17 & 0.0887 \\
\hline had17 & 0.8496 & afd17 & 0.4084 & tnr17 & 0.0688 \\
\hline mc17 & 0.8445 & idhe10 & 0.4049 & conedu & 0.0519 \\
\hline pibc16 & 0.7241 & fundeba17 & 0.4005 & - & - \\
\hline
\end{tabular}




\begin{tabular}{llllllllllll}
\hline rmd17 & $\vdots$ & 0.6819 & $\vdots$ & idhl10 & $\vdots$ & 0.3862 & $\vdots$ & - & $\vdots$ & - \\
\hline
\end{tabular}

Fonte: Elaboração própria.

Legenda: as variáveis foram identificadas no Quadro 1.

Vinte e oito variáveis, das 33 iniciais, foram removidas do modelo de regressão. Chama a atenção a existência, ou não, do Conselho Municipal de Educação (conedu: $p$-value $=0.0519)$, a taxa de não resposta $(\operatorname{tnr} 17: p$-value $=0.0688)$ e a taxa da distorção idade-série (tnr17: p-value $=0.0887$ ). Estas variáveis teriam sido incluídas na equação se fosse definido o nível de significância em 10\% ( $p$-value < 0,1). Nesta consideração, o poder de explicação da equação de regressão final teria o R2 $(R$-sqared $)=0,7037$.

No tabela 4, a seguir, evidenciam-se os dados da equação de regressão oferecida pelo aplicativo STATA explicando as variáveis de influência no IDEB, dos municípios paulistas do ano de 2017.

Tabela 4- Dados da regressão

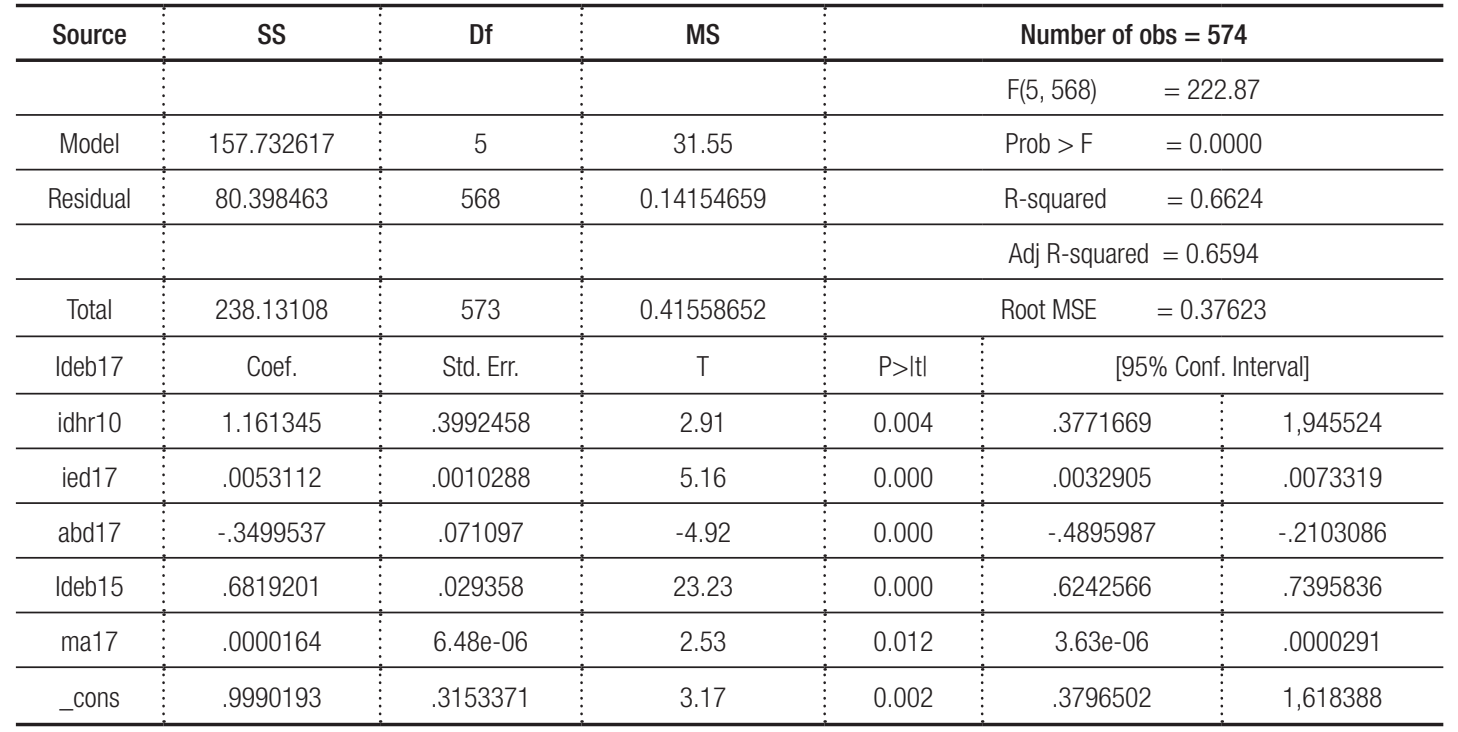

Fonte: Elaboração própria.

Legenda: as variáveis foram identificadas no Quadro 1

0 Tabela 4 evidencia que o modelo econométrico obtido como regressão multivariada tem significância estatística considerável (Prob. F> 0,0000) e que pode explicar 66,24\% $(R$-squared $=0,6624)$ do comportamento da variável dependente, ou seja, o IDEB do ano de 2017 das redes municipais em São Paulo. Como estas variáveis têm, individualmente, significância estatística a 5\%, indicam excelente combinação de foco na gestão da melhoria do IDEB do ensino fundamental, de cada município.

A equação de regressão para estimação do IDEB da rede municipal do ensino fundamental do ano de 2017 dos municípios paulistas, considerando as variáveis com significância estatística é definida da seguinte forma: 
IDEB2017 = 1,161345 idhr10 + 0,0053112 ied17 - 0,3499537 abd17 + 0,6819201 Ideb15 + 0,0000164 ma17

Obs.: As variáveis foram descritas no Quadro 1 e estão analisadas individualmente a seguir.

Tabela 5- Índice de Desenvolvimento Humano dimensão Renda (idhr10) dos municípios paulistas em 2010

\begin{tabular}{|c|c|c|c|c|}
\hline \multirow{2}{*}{ Faixa da população } & \multicolumn{4}{|c|}{ IDHR2010 } \\
\hline & Média & Menor vlr. & Maior vir. & Desvio Padrão \\
\hline 1 & 0,70 & 0,60 & 0,85 & 0,03 \\
\hline 2 & 0,72 & 0,59 & 0,82 & 0,03 \\
\hline 3 & 0,75 & 0,66 & 0,89 & 0,04 \\
\hline 4 & 0,77 & 0,67 & 0,86 & 0,05 \\
\hline 5 & 0,79 & 0,75 & 0,83 & 0,06 \\
\hline Total & 0,72 & 0,59 & 0,89 & 0,04 \\
\hline
\end{tabular}

Fonte: Elaboração própria.

Legenda: faixa da população conforme Tabela 2.

O IDH dimensão Renda (idhr10) está positivamente relacionado ao IDEB dos municípios paulistas. Estima-se que o aumento de 1,16 pontos no IDHR refletirá o aumento de 1 ponto no IDEB do respectivo município. Famílias melhores providas de recursos econômicos têm melhores condições de acesso a escolas nas quais seus filhos têm melhores desempenhos no IDEB. Este resultado está alinhado com a descoberta de Gomes et al. (2016) e Dittrichi (2007). Superar a dicotomia antagônica entre renda e aprendizado é um desafio do estado brasileiro que não foi superado mesmo pela NGP (LOURENÇO et al., 2016, p. 40). Evidência contrária à afirmação de Oliveira (2010) para quem o "desempenho discente não está diretamente relacionado às diferenças econômicas e sociais dos municípios.” (OLIVEIRA, 2010, p. 129).

Tabela 6- Índice de Esforço Docente (ied17) dos que atuam nas redes municipais do ensino fundamental no Estado de São Paulo em 2017, por faixa da população

\begin{tabular}{|c|c|c|c|c|}
\hline \multirow{2}{*}{ Faixa da população } & \multicolumn{4}{|c|}{ Taxa de Esforço Docente } \\
\hline & Média & Menor vir. & Maior vir. & Desvio Padrão \\
\hline 1 & 56,66 & 8,30 & 100,00 & 19,73 \\
\hline 2 & 50,41 & 12,80 & 100,00 & 15,80 \\
\hline 3 & 49,84 & 18,70 & 89,60 & 14,44 \\
\hline 4 & 47,26 & 18,80 & 86,00 & 19,06 \\
\hline 5 & 57,20 & 50,10 & 64,30 & 10,04 \\
\hline Total & 52,80 & 8,30 & 100,00 & 17,68 \\
\hline
\end{tabular}

Fonte: elaboração própria.

Legenda: faixa da população conforme tabela 2.

A variável ied17 reflete as proporções de docentes que desenvolvem menor nível de esforço na função. Evidencia que quanto maior a proporção de docentes com menor 
esforço há melhor (ou mais alto) IDEB no município. Pode-se avaliar o nível de influência do comprometimento físico e intelectual para a necessária adaptação ao desafio de ser professor do ensino fundamental nas redes analisadas. Professores com até 150 alunos por turno tem alunos com melhores desempenhos na Prova Brasil.

Como os município com mais de 1 milhão de habitantes e aqueles com até 30 mil habitantes tem melhores capacidades financeiras para a contratação de maior quantidade de professores (mais de 1 milhão de habitantes) e pela menor quantidade de alunos e menores deslocamentos (até 30 mil habitantes), estes apresentam os melhores desempenho neste indicador. Estes resultados corroboram com os achados de Oliveira (2010), Dittrich (2010) e Vidal e Vieira (2011), ao afirmarem que "A dimensão Infraestrutura Física e Recursos Pedagógicos mostra-se um campo crítico nos municípios fluminenses, demandando um olhar mais atento dos gestores políticos.” (VIDAL; VIEIRA, 2011, p. 128).

Tabela 7- Taxa do abandono (abd17) dos alunos do ensino fundamental nos municípios brasileiros no ano de 2017

\begin{tabular}{|c|c|c|c|c|c|}
\hline \multirow{2}{*}{ Faixa da população } & \multicolumn{5}{|c|}{ Taxa de abando do ensino fundamental } \\
\hline & Média & Menor vir. & Maior vir. & Desvio Padrão & Estimativa* \\
\hline 1 & .0839552 & 0 & 1.5 & .2446507 & 143 \\
\hline 2 & .15 & 0 & 1.6 & .2754493 & 683 \\
\hline 3 & .1508929 & 0 & .7 & .1750138 & 1.519 \\
\hline 4 & .2681818 & 0 & 1 & .2732283 & 1.204 \\
\hline 5 & .15 & .1 & .2 & .0707107 & 89 \\
\hline Total & .1265625 & 0 & 1.6 & 2499090 & 3.638 \\
\hline
\end{tabular}

*Estimativa da quantidade de alunos que abandonaram o ensino fundamental no ano de 2017 com base na quantidade de matriculados e da taxa de abandono de cada município.

Fonte: Elaboração própria.

Legenda: faixa da população conforme Tabela 2.

A taxa de abandono pelos alunos do ensino fundamental está negativamente correlacionada com o IDEB de 2017, como esperado. 0 coeficiente na equação de regressão estimada (-0,349953), indica que o IDEB dos municípios paulistas pode melhorar 1 ponto a cada 3\% de diminuição da taxa de abandono. A coluna estimativa na Tabela 7 mostra que pouco mais de 3,6 mil alunos abandonaram o ensino fundamental no ano de 2017, nestas redes de ensino. Destes, os municípios das faixas 1 a 4, com alto desvio padrão, mostram que este não é um problema de todos. Esta constatação corrobora a afirmação de Rezende e Januzzi (2008, p. 144) de que a redução do abandono escolar ainda é uma das dimensões relevantes do desenvolvimento da educação no país e de Dittrichi (2010) para quem os gestores devem:

[...] se comprometer com parte da solução dos problemas detectados pelas avaliações, implementando políticas que visem garantir ao grupo de escolas que se encontram com os 
desempenhos mais baixos, principalmente quando esse desempenho apresenta vinculação com o nível socioeconômico, que haja uma política efetiva de melhoria diferenciada dessas escolas, para que tais condições privilegiadas consigam compensar parte da estrutura desfavorável dos alunos e alunas dessas escolas. (DITTRICHI, 2010, p. 267).

Assim, há potencial de melhoria no IDEB nos municípios com taxas de abandono escolar mais elevadas, ou seja, programas que induzam a permanência dos alunos nas escolas tem endereço certo.

Tabela 8- Gasto médio com remuneração de profissionais da educação por aluno matriculado (ma17) nas redes municipais do ensino fundamental dos municípios paulistas em 2017, categorizados por faixa da população

\begin{tabular}{|c|c|c|c|c|}
\hline \multirow{2}{*}{ Faixa da população } & \multicolumn{4}{|c|}{ Gasto médio por aluno matriculado } \\
\hline & Média & Menor valor & Maior valor & Desvio Padrão \\
\hline 1 & $8.456,74$ & $1.574,02$ & $46.744,79$ & $5.140,79$ \\
\hline 2 & $6.193,08$ & 532,55 & $21.004,93$ & $2.222,50$ \\
\hline 3 & $6.029,19$ & $1.458,62$ & $13.232,57$ & $2.039,93$ \\
\hline 4 & $5.537,45$ & $7.096,93$ & $9.724,32$ & $2.348,73$ \\
\hline 5 & $6.661,15$ & $5.442,45$ & $7.879,86$ & $1.723,51$ \\
\hline Todos & $7.083,66$ & 532,55 & $46.744,79$ & $3.879,85$ \\
\hline
\end{tabular}

Fonte: Elaboração própria.

Legenda: faixa da população conforme Tabela 2.

Observa-se que os municípios com até 30 mil habitantes tem média de $\mathrm{R} \$ 8,4$ mil reais; porém, o maior valor é cinco vezes superior à média e quase 30 vezes maior do que o menor valor desta categoria de município. Os municípios com população entre 50 mil e 300 mil habitantes têm o menor valor médio de $\mathrm{R}$ \$,0 mil reais, o que mostra ganho de escala das redes de ensino. 0 menor valor de gasto médio por aluno é de 532 reais, representando 8,5\% da média e o maior valor é 39 vezes superior a este, na mesma faixa de município. Estas mesmas cidades, por outro lado, conforme análises adicionais, têm alta média do gasto orçamentário por aluno com compras de materiais e serviços (md17), indicação de que podem ter contratação de pessoal por entidades terceirizadoras dos serviços educacionais. Nas demais faixas populacionais os valores médios, maiores e menores estão relativamente estáveis, haja vista o desvio padrão ser bem inferior em relação às duas primeiras faixas populacionais.

Em análise complementar, avaliou-se que a média do gasto com pessoal próprio das redes municipais do ensino fundamental (ma17) guarda alta significância estatística com a adequação da formação docente (afd17), com o índice de esforço docente (ied17), com a proporção de docentes com curso superior (dsu17), com o índice de regularidade docente (ird17), com a remuneração média do docente (rmd17), com o número de alunos por turma (atu17) e com o valor médio por aluno recebido pelo município das transferências para o FUNDEB (fundebal7). A adequada formação para os conteúdos (afd17) em nível 
da educação superior (dsu17) dos professores combina-se para potencializar os esforços dos sistemas de ensino municipal, com os processos de aprendizagem dos alunos. Esta constatação enfatiza o papel do gasto total com a educação, devendo ser direcionada prioritariamente para a remuneração docente e como estas estão relacionadas aos aspectos complementares da atuação do docente, relevantes do sistema de ensino. Este achado corrobora com as considerações de Gomes et al. (2016), e Jacomini e Pena (2016), Lourenço et al. (2016) e Gomes et al. (2019), para quem os programas, os materiais e os espaços educacionais trabalham juntos pela qualidade quando bem gerenciados (GOMES et al., 2019, p. 292-293).

Tabela 9- Matriz de correlação das variáveis que compõem a regressão múltipla do IDEB do ano de 2017 , das redes do ensino fundamental dos municípios paulistas

\begin{tabular}{|c|c|c|c|c|c|c|}
\hline & Ideb17 & Ideb15 & idhr10 & ied17 & abd17 & ma17 \\
\hline Ideb17 & 1.0000 & & & & & \\
\hline sig & 0.0000 & & & & & \\
\hline Ideb15 & 0.3695 & 1.0000 & & & & \\
\hline sig & 0.0000 & & & & & \\
\hline idhr10 & 0.0813 & 0.1137 & 1.0000 & & & \\
\hline sig & 0.0449 & 0.0050 & & & & \\
\hline ied17 & 0.3871 & 0.1791 & -0.1828 & 1.0000 & & \\
\hline sig & 0.0000 & 0.0000 & 0.0000 & & & \\
\hline abd17 & -0.4449 & -0.1630 & 0.0885 & -0.2994 & 1.0000 & \\
\hline sig & 0.0000 & 0.0001 & 0.0256 & 0.0000 & & \\
\hline ma17 & 0.2224 & -0.0376 & -0.0604 & 0.1748 & -0.1592 & 1.0000 \\
\hline sig & 0.0000 & 0.3549 & 0.1284 & 0.0000 & 0.0001 & \\
\hline
\end{tabular}

Fonte: elaboração própria.

Conforme se verifica no Tabela 9 acima, o nível da correlação univariada entre as variáveis que compõem o modelo de regressão é de baixa a fraca intensidade; por outro lado o nível de significância estatística desta correlação é alto $(p$-value $<0,05)$ para a maior parte das correlações. Esta análise consolida estas variáveis como as principais causas da variação do IDEB do ano de 2017, das redes do ensino fundamental dos municípios paulistas que se combinam para a produção de um evento ou fenômeno (FÁVERO, 2015, p. 44; HAIR et al., 2009, p. 100).

\section{Discussão}


As políticas públicas são fenômenos complexos e sua análise exige capacitação técnica, conhecimento com fundamentação científica bem como dedicação para sua adequada compreensão. Conforme afirma Sechi (2015, p. 1):

A análise de problemas públicos visa melhorar o processo decisório público com o uso de métodos e técnicas de análise de problemas (problem analysis) e análise de soluções (soution analysis) para auxiliar nas decisões e na estruturação de políticas, leis, programas, campanhas, projetos ou ações públicas.

Este estudo mostra que o resultado da política do ensino fundamental dos municípios paulistas medido pelo IDEB é influenciado por interessante e pequena combinação de variáveis. A condição pré-existente, mensurada pelo IDEB da avaliação anterior (2015), com forte poder explicativo da nota atual, representa a força do contexto educacional presente em cada rede municipal, como principal aspecto de mudança na qualidade do ensino fundamental nestas realidades. 0 desafio maior é romper com a inércia na qualidade da educação observada.

Os resultados mostraram que a política educacional de considerar as variáveis estruturais como a do Índice de Desenvolvimento Humano (IDH), componente Renda dos municípios, não discricionária para os gestores das redes, não pode ser transformada por ações diretas. Isso implica em analisar a condição socioeconômica e cultural das famílias para integrá-las no processo de estimulação e desenvolvimento dos alunos.

Por outro lado, o gasto médio com a remuneração dos servidores públicos da educação (professores, funcionários e dirigentes da rede local) é uma das variáveis de forte impacto e desdobramentos no IDEB de 2017 das redes. Há que se avaliar que esta é uma preocupação consolidada na gestão de políticas do ensino fundamental, haja vista a inclusão dos aspectos da valorização dos profissionais da educação quando da renovação do FUNDEF para o FUNDEB (BRASIL, 2019d) e também identificadas por Gomes et al. (2016) e Lourenço et al. (2016). Equalizar as remunerações para o conjunto de municípios, bem como valorizar o professor por uma remuneração justa e condizente com seu papel social, é o passo inicial.

Os dados mostram, em consistência, que o esforço docente é influenciador dos resultados no IDEB de 2017 destas redes municipais. Diminuir a quantidade de turmas, deslocamentos dos professores e a quantidade de alunos por turma são evidências de que a qualidade no atendimento educacional em ambientes de mais fácil gestão e atuação docente são aspectos determinantes para a qualidade do aprendizado e da permanência do aluno na rede. A remuneração docente e sua atuação em sala são determinantes para a qualidade do ensino que será observado com programas e ações próprias para diminuir o esforço do docente, no cumprimento de sua nobre missão de educar. A estruturação de carreiras docentes estimulantes da permanência do professor com vínculo em um só município é um bom caminho.

A taxa de abandono escolar é também condição que pode ser trabalhada com programas específicos. A identificação das condições do abandono, suas motivações e o perfil do aluno podem ser estabelecidas por programas específicos. As 644 redes municipais que consomem mais de 17,6 bilhões de reais ao ano tem potencial para instituir equipes 
de acompanhadores dos abandonos, como ação concreta para a melhoria do IDEB uma vez que "foi possível observar o acolhimento ou associação do Ideb à noção de qualidade educacional." (SANCHES, 2017, p. 151).

\section{Conclusão}

Este estudo procurou identificar quais variáveis influenciaram, com significância estatística, o IDEB do ano de 2017 dos municípios paulistas. Com o uso de 33 variáveis e o método dos Mínimos Quadrados Ordinários (MQ0) com o procedimento stepwise produziu-se conhecimentos inéditos de interesse de gestores e responsáveis pela implementação das políticas educacionais nos municípios.

Os resultados apontam que a condição inicial do ensino no ciclo avaliativo (IDEB de 2015), o gasto médio por aluno com a remuneração dos profissionais de educação, o nível do esforço docente, a taxa de abandono escolar nas redes municipais e o índice de desenvolvimento humano dimensão renda (IDHR) formam o conjunto de variáveis que podem explicar mais de 66\% da variação do IDEB do ano de 2017.

Avaliar as relações intrínsecas bem como os detalhes de como estas variáveis são operacionalizadas e implementar ações em planos, programas e projetos para fortalecimento das dimensões refletidas por estas variáveis, tem o potencial de trazer melhorias para a educação nos municípios do Estado com maior nível de eficácia, se comparadas às demais que não foram contempladas pelo modelo de regressão. Estas considerações são fortalecidas pelos estudos referidos e os resultados deste trabalho, apontando para a melhoria da gestão dos sistemas de educação como passo relevante para a qualidade da educação. A diminuição da quantidade de alunos por turma e/ou da quantidade de turnos de trabalho do professor são exemplos claros e alcançáveis por gestores que gerenciaram gastos públicos na ordem de 16 bilhões de reais no ano de 2017, para atender a uma população de mais de 1,8 milhões de estudantes. A implementação de programas para diminuir o abandono das escolas nos municípios onde este problema se mostra relevante é uma ação desejável com frutos significativos.

Há que se considerar a menor, mas presente influência significativa $(0,05<p$-value $>0,10$ ) de variáveis como a taxa de distorção idade-série, a taxa de não respostas (tnr17) bem como a existência, ou não, do Conselho Municipal de Educação (em oito municípios não há este Conselho instituído, segundo dados da presente pesquisa), como variáveis com potencial de influenciar o IDEB dos municípios paulistas em 2017.

Os estudos publicados bem como os resultados do presente trabalho corroboram com a implementação de ações com forte potencial de mudanças das não tão adequadas condições do ensino fundamental das redes públicas municipais, no estado de São Paulo. Neste sentido, novos estudos com dados primários de natureza qualitativa e quantitativa podem ser desenvolvidos para aprofundar a avaliação dos melhores caminhos para a educação paulista e brasileira. Como o componente professor do ensino fundamental nos municípios apareceu de forma insistente nos resultados do presente estudo e em outros indicados na literatura, uma primeira investigação sobre como estão estruturadas, desenvolvidas e operacionalizadas as carreiras dos profissionais do ensino fundamental 
parece ser a mais urgente. Aspectos da definição e desenvolvimento da carreira docente são os mais prementes.

\section{Referências}

ALVES, Maria Tereza Gonzaga; SOARES, José Francisco. Contexto escolar e indicadores educacionais: condições desiguais para a efetivação de uma política de avaliação educacional. Educação e Pesquisa, São Paulo, v. 39, n. 1, p. 177-194, jan./mar. 2013.

ALVEZ, Thiago; SILVA, Rejane Moreira. Estratificação das oportunidades educacionais no Brasil: contextos e desafios para a oferta de ensino em condições de qualidade para todos. Educação \& Sociedade, Campinas, v. 34, n. 124, p. 851-879, 2013.

BOUERI, Rogério; ROCHA, Fabiana; RODOPOULOS Fabiana. Avaliação da qualidade do gasto público e mensuração da eficiência. Brasília, DF: Ministério da Fazenda, 2015.

BRASIL. Decreto Nº 6.094, de 24 de abril de 2007. Diário Oficial da União, Brasília, DF, 25 abr. 2007. Disponível em: http://www.planalto.gov.br/ccivil_03/_ato2007-2010/2007/decreto/d6094.htm. Acesso em: fev. 2019.

BRASIL. Instituto Brasileiro de Geografia e Estatística. Conheça cidades e estados do Brasil. Brasília, DF: IBGE, 2020a. Disponível em: https://cidades.ibge.gov.br/. Acesso em: abr. 2019.

BRASIL. Instituto Nacional de Estudos e Pesquisas Educacionais Anísio Teixeira. IDEB - Índice de Desenvolvimento da Educação Básica. Brasília, DF: INEP, 2019a. Disponível em: http://ldeb.inep.gov. br/. Acesso em: fev. 2019.

BRASIL. Instituto Nacional de Estudos e Pesquisas Educacionais Anísio Teixeira. Indicadores educacionais. Brasília, DF: INEP, 2019c. Disponível em: http://inep.gov.br/web/guest/indicadores-educacionais. Acesso em: abr. 2019.

BRASIL. Instituto Nacional de Estudos e Pesquisas Educacionais Anísio Teixeira. Nota Técnica - Índice de Desenvolvimento da Educação Básica - Ideb. Brasília, DF: INEP, 2019b. Disponível em: http:// download.inep.gov.br/educacao_basica/portal_ideb/o_que_e_0_ideb/Nota_Tecnica_n1_concepcaolDEB. pdf. Acesso em: mar. 2019.

BRASIL. Ministério da Educação. Fundeb: apresentação. Brasília, DF: MEC, 2019d. Disponível em: http:// portal.mec.gov.br/fundeb. Acesso em: abril 2019.

BRASIL. Ministério da Saúde. Índice de Gini da renda domiciliar per capita. Brasília, DF: MS, 2019e. Disponível em: http://tabnet.datasus.gov.br/cgi/ibge/censo/cnv/ginisp.def. Acesso em: abr. 2019.

BRASIL. Secretaria do Tesouro Nacional. Siconfi Sistema de informações contábeis e fiscais do setor público brasileiro. Brasília, DF: STN, 2020b. Disponível em: https://siconfi.tesouro.gov.br/siconfi/index.jsf. 
Acesso em: abr. 2019.

CORRAR, Luiz João; PAULO, Edilson; DIAS FILHO, José Maria. Análise multivariada para os cursos de administração, ciências contábeis e economia. São Paulo: Atlas, 2014.

DITTRICH, Douglas Danilo. Impactos da política educacional do município de Curitiba-PR sobre a melhoria do IDEB dos anos iniciais do ensino fundamental. 2010. 290 p. Dissertação (Mestrado em Educação) - Universidade Federal do Paraná, Curitiba, 2010.

FÁVERO, Luiz Paulo. Análise de dados: modelos de regressão com excel, stata e spss. São Paulo: Campus; Elsevier, 2015.

FÁVERO, Luiz Paulo et al. Métodos quantitativos com stata. São Paulo: Campus; Elsevier, 2014.

FRANKLIN, Rodrigo Dias. Avaliação da qualidade da educação através do IDEB: 0 caso de Trajano de Moraes/RJ. 2011, 242 p. Dissertação (Mestrado em Educação) - Faculdade de Educação da Universidade Federal do Rio de Janeiro, Rio de Janeiro, 2011.

GOMES, Maria Helena Scalabrin Cardoso; BRESCIANI, Luis Paulo; AMORIM, Wilson Aparecido. Políticas sociais, educação e desenvolvimento econômico: busca Por evidências correlacionais a partir das avaliações do IDEB de três municípios paulistas. Gestão \& Regionalidade, São Caetano do Sul-SP, v. 32, n. 94, p. 36-51, 2016.

GOMES, Valdete Aparecida Fernandes Moutinho; NUNES, Célia Maria Fernandes; PADUA, Karla Cunha. Condições de trabalho e valorização docente: um diálogo com professoras do ensino fundamental I. Revista Brasileira de Estudos Pedagógicos, Brasília, DF, v. 100, n. 255, p. 277-296, ago. 2019.

GUSMÃo, Joana Buarque de. A construção da noção de qualidade da educação. Ensaio, Rio de Janeiro, v. 21, n. 79, p. 299-322, abr./jun. 2013.

HAIR, Joseph F. et al. Análise multivariada de dados. Porto Alegre: Bookman, 2009.

JACOMINI, Maria Aparecida; PENNA, Marieta Gouvêa Oliveira. Carreira docente e valorização do magistério: condições de trabalho e desenvolvimento profissional. Pro-Posições, Campinas, v. 27, n. 2, p. 177-202, ago. 2016.

LOURENÇO, Rosenery Loureiro et al. Determinantes sociais e pedagógicos das notas do IDEB. Revista Pensamento Contemporâneo em Administração, v. 11, n. 4, p. 27-43, 2017.

MORAES, Vinicius Macedo de. Análise da eficiência em educação fundamental das municipalidades mediante a elaboração de uma tipologia de municípios: mestrado em gestão de políticas públicas da EACH/USP. São Paulo: EACH, 2018.

OLIVEIRA, Adailda Gomes de. Políticas públicas educacionais dos municípios do estado do RJ: relações com os indicadores de qualidade 2005 e 2007. 2010. 147 p. Dissertação (Mestrado) - Pontifícia 
Universidade Católica do Rio de Janeiro, Rio de Janeiro, 2010.

REZENDE, Leonardo Milhomem de; JANNUZZI, Paulo de Martino. Monitoramento do plano de desenvolvimento da educação: proposta de aprimoramento do Ideb e de painel de indicadores. Revista do Serviço Público, v. 59, n. 2, p. 121-150, 2008.

SANCHES, Ligia Gonçalez. O Ideb em pesquisas acadêmicas brasileiras entre 2007 e 2015. 2017. Dissertação (Mestrado) - Faculdade de Educação da Universidade de São Paulo. São Paulo, 2017.

SÃO PAULO. Tribunal de Contas do Estado de São Paulo. Contas anuais. São Paulo: TCESP, 2019. Disponível em: https://www.tce.sp.gov.br/contas-anuais. Acesso em: jan. 2019.

SCIELO. Modelo de publicação eletrônica para países em desenvolvimento. São Paulo: SciELO, 2019. Disponível em: https://wp.scielo.org/wp-content/uploads/Modelo_SciELO.pdf. Acesso em: set. 2019.

SECHI, Leonardo. Políticas públicas: conceitos, esquemas de análises, casos práticos. 2. ed. São Paulo: Cengage Learning, 2015.

SPELL. Scientific periodicals eletronic library. Busca de artigos. Maringá: Spell, 2019. Disponível em: http:// www.spell.org.br/. Acesso em: abr. 2019.

STEVENSON, William J. Estatística aplicada à administração. São Paulo: Harbra, 1981.

VIDAL, Eloisa Maia; VIEIRA, Sofia Lerche. Gestão educacional e resultados no IDEB: um estudo de caso em dez municípios cearenses. Estudos em Avaliação Educacional, São Paulo, v. 22, n. 50, p. 419-34, 2011.

WOOLDRIDGE, Jeffrey. Introdução à econometria: uma abordagem moderna. 3. ed.São Paulo: Cengage Learning, 2016.

Recebido em: 24.10.2019

Revisado em: 01.09.2020

Aprovado em: 16.03 .2021

Jaime Crozatti é doutor em controladoria e contabilidade pela Faculdade de Economia, Administração, Contabilidade e Atuária da Universidade de São Paulo (FEA/USP). É professor dos cursos de mestrado e bacharelado em gestão de políticas públicas da Escola de Artes, Ciências e Humanidades da Universidade de São Paulo (EACH/USP) e membro do Observatório Interdisciplinar de Políticas Públicas José Renato Araújo. 